\title{
PLASTIC INSTABILITIES IN FATIGUE IN AILi ALLOYS : FROM THE MECHANICAL ASPECTS TO THE NANOMETRIC INVESTIGATIONS
}

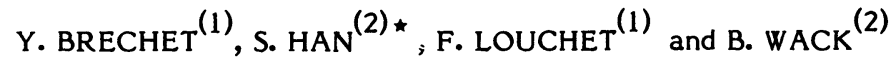 \\ (1) I.N.P.G. - L.T.P.C.M.-E.N.S.E.E.G., B.P. 75, 38402 Saint-Martin-d'Hères Cedex, France \\ (2) I.M.G., B.P. 68, 38402 Saint-Martin-d'Hères Cedex, France
}

Two types of binary aluminium alloys were studied : alloy A (0.7 wt \% Li solid solution) and alloys $B$ and $C(2.5$ wt \% Li with small ( $\sim 10 \AA)$ and large $(R \simeq 200 \AA) \delta^{\prime}$ coherent and ordered precipitates).

The central part of the fatigue specimens is a thin tube (length $30 \mathrm{~mm}$, outside radius $15 \mathrm{~mm}$, ins $i-$ de radius $12 \mathrm{~mm}$ ). All the tests are performed in symmetrical torsion with an imposed strain amblitude $\Delta \varepsilon$ of $\pm 0.3 \%$ or $\pm 0.5 \%$, at a strain rate of $3 \times 10^{-5} s^{-1}$, the strain being measured by strain gages).

The analysis of the experimental results show a mechanical hysteres is behaviour associated with strain hardening. The deformation is irreversible from the very beginning (no yield point)(fig. 1). The strain hardening depends on the type of alloy and on the precipitate diameter. This behaviour can be modelized by a discrete memory constitutive scheme [1].

In the case of alloy $B$, instabilities appear along the plateau of quasi-plasticity (fig. 1), since the 1st loading branch ; on analogic recordings the instabilities look like the beginning of an inversion followed by a reloading. These little cycles are so small that they appear as lines, whose slope is parallel to that of the loading branch after inversion. These instabilities do not appear in alloy A. For alloy $C$, the strain amplitude was too small to conclude.

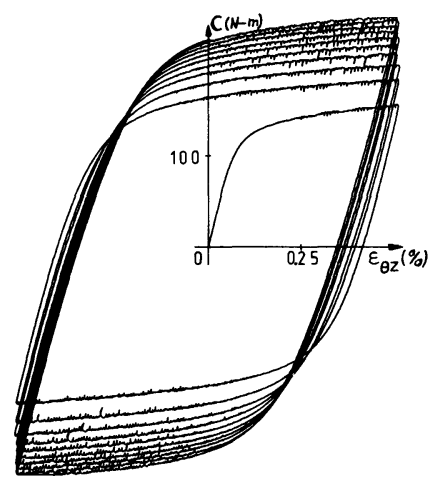

Fig. 1 - Low cycle fatigue of $A 72.5$ wt \% Li alloy with small precipitates (alloy B) showing instabilities on the plateau of quasi-platicity (analogic recording)

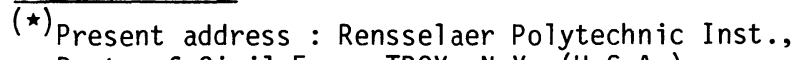
Dept. of Civil Eng., TROY, N.Y. (U.S.A.)
After the macroscopic fatigue tests, microsamples are cut for TEM and STEM observations and microanalysis, and in situ fatigue experiments.

In situ fatigue tests on alloys $B$ show a localized slip of dislocations, in constrast with the homogeneous slin observed in the cell structure of alloy A. Superlattice dark field observations show that slip bands are deprived from $\delta$ ' precipitates. EELS and filtered images obtained in STEM [2] prove that the total Li concentration within the bands is close to that of the solid solution.

A simple model is proposed for the formation of the bands. It is shown that the APB's induced by shearing modify strongly the energy balance which defines the nucleation critical radius, which increases with the cumulative strain $\varepsilon$, and becomes infinites for a critical local cumulative strain $\varepsilon_{c}$. The sheared precinitates then dissolve inside the bands, the excess of Li migrates by diffusion across the band, inducing precipitate coarsening on both sides of the band, as observed experimentally (snowplough effect).
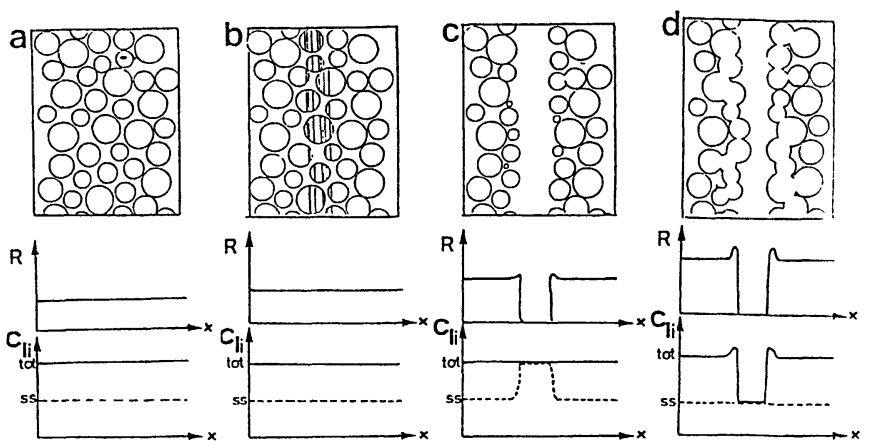

Fig. 2 - Formation of a precipitate free band by dissolution of $\delta^{\prime}$ precipitates :

a) initial state

b) formation of antiphase boundaries

c) dissolution of precipitates in the band, and correlative local increase of $L i$ concentration in the solid solution

d) Li diffusion and coarsening of precipitates on the band edges.

\section{References :}

1 HAN S. and WACK B., Res. Mechanica 1987, 20, pp. $1-28$

2 BRECHET Y., LOUCHET F., MARCHIONNI C. and VERGERGAUGRY J.L., 1987, Phil. Mag., underpress. 